\title{
AVERIGUAÇÃO DO PORQUÊ DAS DISTINTAS VISÕES SOBRE O ARMAMENTO NUCLEAR DE CADA NOVO GOVERNO DOS ESTADOS UNIDOS DA AMÉRICA NO PÓS-GUERRA FRIA
}

Felipe Dalcin Silva ${ }^{1}$

\section{RESUMO}

O objetivo deste artigo é investigar os fatores que influenciaram as mudanças de perspectiva em relação ao armamento nuclear dos Estados Unidos da América (EUA) em cada governo, no pósGuerra Fria. Para que isto seja atingindo é necessário levar em conta os seguintes fatores: 1. O que explica as percepções distintas de ameaça nuclear que Washington encarou contra si e contra seus aliados a partir do tempo e; 2. O porquê de cada administração governamental estadunidense requisitar determinadas atitudes do país em relação a manutenção e ou desenvolvimento e ou desmantelamento de sistemas de armas nucleares. As fontes primárias que serviram de base para a elaboração deste texto foram os documentos de defesa dos EUA, no pós-Guerra Fria, que discorrem sobre armas nucleares, principalmente o Nuclear Posture Review (NPR), o qual apresenta uma versão distinta para cada novo governo que toma posse da presidência em Washington. Já as fontes secundárias são artigos, livros e notícias que tratam destes mesmos temas. A hipótese deste trabalho é que a visão irregular dos diferentes governos nos EUA pode ser explicada, sobretudo, pelo contexto temporal que cada administração está inserida. Esta pesquisa apresenta grande relevância a medida que expõe e compara a visão das administrações estadunidenses sobre as armas nucleares, principalmente dos fatores que explicam discrepâncias em determinados aspectos ao longo do tempo, auxiliando também em um melhor entendimento da atual postura nuclear estadunidense no governo de Donald Trump.

\footnotetext{
1 Mestrando no Programa de Pós-Graduação em Estudos Estratégicos Internacionais (PPGEEI) da Universidade Federal do Rio Grande do Sul (UFRGS). Bacharel em Relações Internacionais pelo Centro Universitário Curitiba (UNICURITIBA). E-mail para contato: felipedalcinsilva@yahoo.com. ORCID: <https://orcid.org/0000-0001-7107$\underline{7513}>$.
} 
Palavras-chave: Estados Unidos da América, Armas Nucleares, Pós-Guerra Fria, Nuclear Posture Review.

\section{INTRODUÇÃO}

$\mathrm{O}$ intuito deste texto é investigar os fatores que explicam as diferença de visão sobre o armamento nuclear estadunidense em cada novo governo no pós-Guerra Fria. Para isto é fundamental a leitura do Nuclear Posture Review (NPR) de cada administração. Basicamente este documento aborda os seguintes pontos: 1. Percepção de ameaça de possíveis ataques com armamento nuclear contra os Estados Unidos da América (EUA) e contra os aliados estadunidenses;

2. O papel das forças nucleares para o planejamento militar-estratégico norte-americano; e 3. Avaliação dos sistemas de armas, se, por exemplo, há necessidade de produzir novos tipos de armas nucleares ou até mesmo tirar de serviço determinado sistema de arma.

Este artigo acredita que o primeiro ponto indicado acima é o principal condutor para o planejamento dos governos norte-americanos em relação as armas nucleares. O Office of the Deputy Assistant Secretary of Defense for Nuclear Matters (ODASDNM) (2020, p. 3-5) - o qual fornece assistência ao secretário de defesa em assuntos nucleares - aponta que há três eras nucleares: $1^{\mathrm{a}}$. De 1945 até 1991, período da Guerra Fria em que na ordem bipolar os Estados Unidos e a União das Repúblicas Socialistas Soviéticas (URSS) vislumbravam as armas nucleares como essenciais para o planejamento de guerra de ambas as partes; $2^{\text {a }}$. De 1991, ano do esfacelamento soviético, até meados da segunda década do século XXI, em que ameaças advindas de Estados não centrais e organizações terroristas fizeram como que o papel do arsenal nuclear diminuísse drasticamente para o líder da nova ordem unipolar, os EUA; e $3^{\text {a }}$ De meados da segunda década do século XXI em diante, em que a volta da competição entre as grandes potências em uma ordem internacional a qual empeza a ter características de um sistema internacional multipolar entre norte-americanos, chineses e russos, torna mais uma vez as armas nucleares como o cerne da preocupação securitária norte-americana.

Neste artigo percorreremos as mudanças da segunda era nuclear - governos Clinton, Bush e parte do governo Obama - para a terceira era nuclear, a qual inicia em meados da administração Obama e é escancarada no atual governo Trump. Apesar de nuances entre os três primeiros 
governos estadunidenses, paulatinamente vemos mudanças as quais levaram a conjuntura atual. Estas percepções levantas por este artigo são essenciais para entendermos a visão do atual governo Trump em relação ao armamento nuclear.

Para elaborar este artigo foi necessário a consulta de fontes primárias e secundárias. As primeiras são basicamente documentos de defesa, já, as segundas são livros, artigos e notícias que abordam os temas trabalhados neste texto.

\section{GOVERNO BILL CLINTON (1993-2001)}

O governo do democrata Bill Clinton foi o primeiro iniciado no pós-Guerra Fria. Neste contexto as armas nucleares, grande símbolo da estabilidade bipolar entre soviéticos e norteamericanos, começaram a ser vistas com menos relevância. Isto se deve ao fato de que na nova conjuntura unipolar, EUA como esteio da governança global, não se era mais esperado o choque entre as grandes potências, em que a possibilidade de conflito militar direto, até mesmo com o emprego de armas nucleares, era vislumbrada como mínima. Assim, as armas nucleares perderam o papel de preponderância no que tange o planejamento estratégico de defesa dos EUA. É possível ver o reflexo disto na diminuição brusca que os estadunidenses fizeram nos seus gastos com armamento nuclear: em 1984, por exemplo o gasto anual com este tipo de armamento foi em torno de 47 bilhões de dólares, já em 1994 este valor caiu para 13 bilhões de dólares (ROBERTS, 2016, p. 15-18).

As preocupações, em termos de segurança internacional, de Washington, quedou sobre os Estados considerados impares no sistema internacional, os quais poderiam deturpar a segurança e os interesses internacionais/locais dos EUA e dos aliados estadunidenses, Iraque, por exemplo. Além disto, outro ponto de enfoque norte-americano foi a preocupação com organizações terroristas. Apesar destes dois tipos de ameaças poderem criar/adquirir armas de destruição em massa (ADM) - além das armas nucleares, armas químicas, armas biológicas e armas radiológicas -, acreditava-se que o aprimoramento constante das armas convencionais seriam o bastante para dissuadir e retaliar qualquer ataque com ADM, principalmente das armas biológicas e químicas, sendo então um indicativo que o armamento nuclear poderia ficar reservado somente como ferramenta de dissuasão e retaliação nuclear (KRISTENSEN, 1995).

Porém, apesar de menor espaço, o armamento nuclear ainda detinha importância para os Estados Unidos. Para entendermos melhor o papel deste tipo de armamento na administração 
Clinton, é necessário expor os principais pontos do NPR 19942: 1. As armas nucleares teriam relevância menor no planejamento estratégico de defesa dos Estados Unidos; 2. Devido a isto, não era mais necessário manter arsenal nuclear da mesma dimensão do que da época da Guerra Fria $; 3$. Contudo, os EUA devem manter quantidade necessária de sistemas de armas nucleares, as quais sejam capazes de dissuadir qualquer eventual adversário, sobretudo a nível de emprego de armas nucleares; 4. Washington garantia a manutenção do compromisso de proteger seus aliados da Organização do Tratado do Atlântico Norte (OTAN) e seus aliados asiáticos4; e 5. Os norteamericanos manteriam todas as salvaguardas em relação a proteção e know-how de material nuclear sensível (KRISTENSEN, 1995).

Para que outros países também diminuíssem seus respectivos arsenais nucleares, os EUA defendia que a cláusula VI do Tratado de Não-Proliferação Nuclear (TNP)s deveria servir de condutor para o corte do número de armas nucleares ao redor do globo. Além do mais, a administração Clinton empreenderia esforços para que a implementação de acordos como o START $\mathrm{I}_{6}$ e $\mathrm{II}_{7}$ fossem aceleradas e que o $\mathrm{CTBT}_{8}$ fosse ratificado pelo senado estadunidense. Agora,

\footnotetext{
2 Este documento foi lançado classificado, os principais pontos foram apresentados posteriormente a impressa em 1995. Para a elaboração deste artigo se consultou as informações que Kristensen (1995) recolheu sobre o conteúdo do NPR 1994, as quais estão disponível em: <https://fas.org/nuke/guide/usa/doctrine/dod/95_npr.htm>.

${ }_{3}$ A quantidade de ogivas nucleares sofreria corte de 50\%; A quantidade de sistemas de armas nucleares estratégicas bombardeiros, misseis balísticos intercontinentais e submarinos lançadores de mísseis balísticos - prontas para uso imediato seria reduzido em $47 \%$; o número de depósitos aonde as armas nucleares ficavam estocadas cairia em $75 \%$ e o número de profissionais com acesso a este tipo de armamento também teria decréscimo de 70\% (ROBERTS, 2016, p. 17-18).

${ }_{4}$ Como Coréia do Sul, Japão e Taiwan.

${ }_{5}$ A sexta cláusula do TNP declarava que os países possuidores de armamento nuclear deveriam trabalhar para criar uma ordem global em que a existência deste tipo de armamento fosse totalmente extinguida (NPT, 1968). A ideia dos EUA era ter um papel de "liderança pelo exemplo". Já que Washington iria diminuir o espaço das suas armas nucleares, era esperado que o restante dos países do sistema internacional ou reduzissem os seus respectivos arsenais nucleares - para aqueles Estados os quais já possuíam este tipo de armamento - ou servisse de mais um incentivo para que novos países não empreendessem esforços para construir suas primeiras armas nucleares.

${ }_{6}$ O Strategic Arms Reduction Talks (START I, sigla em inglês) foi um acordo assinado em 1991 entre a União Soviética e os EUA. Ambas as partes deveriam reduzir seus sistemas de armas nucleares estratégicos para uma quantidade de 10,5 mil. O acordo especificava ainda os seguintes limites: 1,6 mil sistemas de envio de armas nucleares estratégicos; 6 mil ogivas nucleares para estes meios; 4,9 mil mísseis balísticos; 1,540 mil ogivas nucleares em 154 mísseis balísticos intercontinentais lançados pesados; e 1,1 mil ogivas nucleares em mísseis balísticos continentais lançados de plataformas móveis. Ficava acordado também que os dois lados teriam acesso técnico para ver se seu páreo estava cumprindo com as regras do acordo. O START 1 posteriormente, em 2010, seria substituído pelo New START (ODASDNM, 2020, p. 205-206).

${ }_{7}$ O START II pretendia que os Estados Unidos e a Rússia eliminassem os veículos de reentrada independente múltipla dos mísseis balísticos intercontinentais; limitassem o número de ogivas nucleares em mísseis balísticos lançados de submarino para no máximo 1,75 mil; e que cada lado pudesse ter no máximo entre 3 a 3,5 mil ogivas nucleares para estes meios. As negociações empezaram em 1992, todavia, este acordo nunca entrou em vigor, devido a sua não ratificação pelos russos (ODASDNM, 2020, p. 208).

${ }_{8}$ O Comprehensive Nuclear-Test-Ban Treaty (CTBT, sigla em inglês) bane qualquer tipo de teste com armamento nuclear. As negociações deste tratado perduraram entre 1994 e 1996. O presidente Clinton não obteve ratificação deste acordo perante a câmera alta do legislativo estadunidense em 1999. Contudo, vale lembrar que os EUA tem um moratório de não realizar testes nucleares, especificamente testes subterrâneos desde 1992 (ODASDNM, 2020, p. 208).
} 
devemos mapear o contexto e as políticas nucleares da administração do republicano George W. Bush.

\section{GOVERNO GEORGE W. BUSH (2001-2009)}

O NPR 2001, segue a mesma linha do que o NPR 1994 pregava: apesar de concordar que as armas nucleares tem papel fundamental para dissuadir que possíveis adversários empreguem o uso de ADM, sobretudo as nucleares. Porém, o foco dos EUA era investir mais na capacidade convencional. Para administração Bush as maiores ameaças também seriam advindas da possibilidade de organizações terroristas tomarem posse de armas de destruição em massa e de que os Estados do "eixo do mal" ${ }_{10}$ obtivessem ADM, principalmente as nucleares. Para contrapor tais ameaças, Bush defendia até mesmo a realização de ataques preventivos ${ }_{11}$. Todas estas medidas deveriam garantir a manutenção da segurança e dos interesses regionais e globais de Washington e seus aliados (ROBERTS, 2016, p. 21).

Assim como a administração Clinton, o governo Bush defendia acordos e políticas as quais não só diminuíssem as armas nucleares, mas também qualquer tipo de arma de destruição em massa. O então governo norte-americano deixava claro a preocupação com a falta de transparência da China em relação as suas forças nucleares e sua doutrina de emprego de armas nucleares, advertindo que isto poderia causar erros de cálculo em um eventual quadro de tensão política entre as partes, sobretudo devido a uma série de atritos que o governo chinês tem com aliados estadunidenses no leste da Ásia. Com Moscou, Washington buscaria engatilhar acordos que possibilitassem diminuição do arsenal nuclear entre os dois países (EUA, 2002, p. 5; GUTHE, 2016, p. 16)

Apesar da diminuição do arsenal nuclear que o governo Bush planejava orquestrar, através de remanejo das forças nucleares por meio de acordos como o START I e II e outros cortes unilaterais nas forças nucleares do país, a administração Bush enxergava a necessidade de produção de armamento nuclear com maior capacidade de penetração da terra. A justificativa dada era que

\footnotetext{
9 Assim como a versão de 1994, o NPR 2001 foi lançado classificado. O cerne deste documento também foi apresentado à imprensa em 2001. Os dados do documentos usados por este artigo foram disponibilizados pela Universidade de Stanford em: 〈https://web.stanford.edu/class/polisci211z/2.6/NPR2001leaked.pdf $>$.

${ }_{10}$ Estados, que de acordo com o presidente Bush, patrocinavam/auxiliavam organizações terroristas e que buscavam construir armas de destruição em massa. Seriam pertencentes a este grupo: Irã, Iraque, Síria, Líbia e Coréia do Norte.

${ }_{11}$ Isto faz parte do que ficou conhecido como "Doutrina Bush": em que os EUA iniciariam uma guerra preventiva, se necessário, para evitar que Estados obtivessem armas de destruição em massa e ou apoiassem grupos terroristas. Isto foi utilizado como desculpa para invasão do Iraque em 2003. Posteriormente foi descoberto que o então líder iraquiano, Saddam Hussein, não estava investindo na construção de ADMs.
} 
mais de 70 países possuíam estruturas subterrâneas para propósitos militares, totalizando ao redor de 10 mil estruturas com este fim e entre estas mil poderiam estar servindo como depósito de ADM. O NPR 2001 admite a dificuldade de atingir tais alvos já que tais estruturas subterrâneas são mais difíceis de serem destruídas e de serem localizadas. O documento vai adiante alegando que armas convencionais não são adequadas para atingir estes alvos e que a única arma nuclear que os EUA possuem que tem capacidade maior de penetração na terra, a B61-11 12, não apresenta grande efetividade $_{13}$ (EUA, 2001, p. 15-16). Sendo assim, em 2001, a administração Bush requere ao senado fundos para a produção de um novo sistema de arma com maior capacidade de penetração do que a B61-11, o que foi rechaçado diversas vezes pela câmera alta do legislativo norteamericano (ROBERTS, 2016, p. 24-25).

Além do mais, outro enfoque do governo Bush foi a maior aplicação de barreiras antimísseis. Isto acabou levando a saída dos Estados Unidos do $\mathrm{ABM}_{14}$. A saída deste acordo gerou grande descontentamento da Rússia. Mais adiante, o líder russo Vladimir Putin (2018) deixa claro que o maior desenvolvimento de barreiras antimísseis dos EUA e posteriormente também instalações destes sistemas de armas no território da Romênia e da Polônia - países pertencentes a OTAN -, foram mais uma atitude estadunidense para deturpar a capacidade estratégica e dissuasória russa, o que fez com que Moscou empreender grandes investimentos em novos sistemas nucleares efetivos, desde o começo da primeira década do novo milênio, os quais mantivessem, mesmo com as barreiras antimísseis, a capacidade do arsenal nuclear russo de infligir dano aos membros da OTAN ${ }_{15}$. Os EUA alegaram que as barreiras antimísseis visavam na verdade protegerse e proteger os seus aliados de eventuais ataques com mísseis balísticos vindos sobretudo do Irã. Contudo, Putin alega não acredita nesta afirmação estadunidense (JESUS, 2013, p. 88). Aqui temos

\footnotetext{
12 A bomba B61-11 entrou em serviço em 1997. É uma versão modificada da B61-7, tendo como grande diferença a capacidade de penetração maior na terra, o que torna alvos subterrâneos mais suscetíveis a dano. Isto se deve a capa de urânio que o bico da bomba é revestido, ao sistema de difusão e mais um motor de foguete auxiliar que é acoplado na bomba. Tudo isto permite que a B61-11 penetre ao redor de 2 a 3 metros em superfícies mais duras antes de explodir. O rendimento desta bomba é de 400 kilotons (TREVITHICK, 2018).

${ }_{13}$ Todo este esforço é voltado para capacitar as forças estadunidenses de atingirem infraestruturas subterrâneas de possíveis rivais. Países como Irã, Coréia do Norte, China e Rússia, por exemplo, possuem este tipo de estrutura não só para proteger sistemas de armas, também, pessoal - liderança - e estruturas de comando e controle.

${ }_{14}$ O Anti-Ballistic Missile Treaty (ABM), de 1974, foi um tratado entre os EUA e a URSS em que estes dois países só poderiam proteger com barreiras antimísseis duas regiões do seus respectivos território. Os EUA se retiram deste acordo em 2002 (ODASDNM, 2020, p. 200). A ideia do ABM era que não se começasse uma corrida armamentista ainda maior - já que poderia fazer com que os dois lados tivessem que gastar ainda mais na produção de novos mísseis balísticos intercontinentais, os quais pudessem ultrapassar tais barreiras; além do mais, os dois lados poderiam iniciar uma disputa frenética pela construção de melhores barreiras antimísseis, o que poderia criar receio na capacidade dissuasória de ambas as partes, podendo facilitar o erro de cálculo entre elas.
}

${ }_{15}$ Para mais informações do desenvolvimento das forças nucleares da Rússia ver: WOLF, Amy. Russia's Nuclear Weapons. 2019, p. 20-26. Disponível em: 〈https://fas.org/sgp/crs/nuke/R45861.pdf $>$. 
o início de mais um ponto de fricção entre russos e norte-americanos, o que será mais escancarado no governo do democrata Barack Obama - a próxima administração governamental analisada reverberando também posteriormente da visão securitária do governo de Donald Trump.

\section{GOVERNO BARACK OBAMA (2009-2017)}

O democrata Barack Obama assume o cargo de presidente dos EUA em 2009, neste mesmo ano faz um discurso em Praga, capital da República Tcheca, sobre qual seria sua política central em relação as armas nucleares. O democrata expõe que seu governo se esforçaria para criar uma ordem internacional sem armamento nuclear e que esperava que suas políticas fossem o gêneses para que este objetivo se tornasse possível. Entretanto, Obama sabia que isto não podia ser realizado de forma repentina, enquanto houvessem armas nucleares os EUA deveriam ter este tipo de armamento e plenas condições de emprega-los em situações de necessidade (ROBERTS, 2016, p. 29).

O NPR 2010, lançado pela primeira vez desclassificado - o intuito estadunidense era deixar claro para aliados e possíveis adversários quais eram as políticas norte-americanas em relação a este tipo de armamento - serve como atestado documental das intenções da administração Obama em relação as armas nucleares já assinaladas sobretudo com o discurso do então presidente na capital tcheca. De forma resumida, podemos apontar que os seis objetivos principais do NPR 2001 são: 1. Empreender com mais afinco políticas contra a proliferação nuclear e também contra a possibilidade de organizações terroristas obterem armas nucleares $16 ; 2$. Diminuir o papel das armas nucleares estadunidenses como ferramenta dissuasória, através, principalmente, de uma maior investimento em armas convencionais, sobretudo das barreiras antimísseis; 3. Manter a estabilidade estratégica, principalmente com a Rússia, ao passo que os EUA diminuem seu respectivo arsenal nuclear; 4. Proteger os aliados dos EUA - tanto da OTAN quanto asiáticos - de qualquer eventual ameaça ou uso de força, mesmo que nuclear; 5. Manter o arsenal nuclear estadunidense seguro e protegido, contra ataques e contra roubo e ou deturpações; e 6. Criar uma base real para que as armas nucleares possam ser extinguidas no futuro (ROBERTS, 2016, p. 31-32).

\footnotetext{
${ }_{16} \mathrm{O}$ terrorismo nuclear é tratado como a principal ameaça pelo NPR 2010. Isto se deve muito a securitização norteamericana posteriores aos ataques terroristas de 11 de setembro de 2001, planejados e executados pela Al-Qaeda de Osama Bin Laden. O temor é que Estados entregassem dispositivos nucleares a organizações terroristas ou que estas obtivessem este tipo de material através do mercado negro.
} 
Em relação a Rússia, a administração Obama declara que não enxergava este país como um inimigo, mas sim, com um aliado para combater tanto a proliferação nuclear quanto organizações terroristas. Como no governo Bush, o governo Obama demonstrava preocupação com a nebulosa postura nuclear da China, já que os chineses não apresentam com clareza os seus desenvolvimentos militares, principalmente no âmbito das armas nucleares e também da falta de revelação de qual seria a doutrina de emprego de armas de Pequim. A grande preocupação decorrente de fontes Estatais era a possibilidade de que a Coréia do Norte empregasse armas nucleares contra os EUA e ou contra os aliados estadunidenses na Ásia e que Irã construísse suas primeiras armas nucleares.

Como Clinton e Bush, Obama buscaria fortalecer os regimes de controle e ou diminuição de armas nucleares, sobretudo o TNP. Além do mais, em 2010 é assinado o New START com a Rússia. Neste acordo, as partes limitaram o número de ogivas inseridas em sistemas de armas estratégicas, ou seja, a tríade nuclear - bombardeiros, submarinos lançadores de mísseis balísticos e mísseis balísticos intercontinentais - em 1,55 mil. Também ficou estabelecido que: cada bombardeiro poderia carregar apenas uma ogiva nuclear; o limite de plataformas de envio de armas nucleares não poderia passar de 700; e que os dois lados poderiam inspecionar se seu páreo está respeitando as regras do acordo. O New START, se não for renovado, expirará em 2021 (ODASDNM, 2020, p. 210).

Porém, posteriormente a elaboração e ao lançamento do NPR 2010, diversos fatores fizeram com que a visão do administração Obama empezasse a ser diferente em relação a Rússia, a China e as próprias forças nucleares estadunidenses. Este texto agora exibirá os fatores que ajudam a entender a discrepância entre o NPR 2010 e o NPR 2018, o que de acordo com o ODASDNM, escancarará o processo de transição entre a segunda era nuclear para a terceira era nuclear.

Com o fim da Guerra Fria as relações entre norte-americanos e russos, em diversos momentos, beirou mais a cooperação do que fricção política entre as partes. Todavia, a expansão da OTAN em direção ao leste europeu - região considerada por Moscou como zona de influência russa, já que era composta pelos Estados que faziam parte da URSS - iniciada no governo Clinton e ampliada no governo Bush foi vista como uma afronta pelo Kremlin, Ver imagem 1 abaixo. Obama assume o cargo tentado melhorar as relações com os russos através de debates em assuntos de mútuo interesse: a então conjuntura do Oriente Médio, proliferação nuclear e combate ao terrorismo. Neste interim as partes assinam o New START em 2010, o governo Obama até tenta celebrar mais acordos de limitação e controle de armamento nuclear com a Rússia, o que não acaba 
acontecendo devido as barreiras antimísseis instaladas no território de aliados estadunidenses da OTAN (POWASKI, 2019, p. 193-195).

\section{IMAGEM 1 - EXPANSÃO DA OTAN PARA O LESTE EUROPEU}
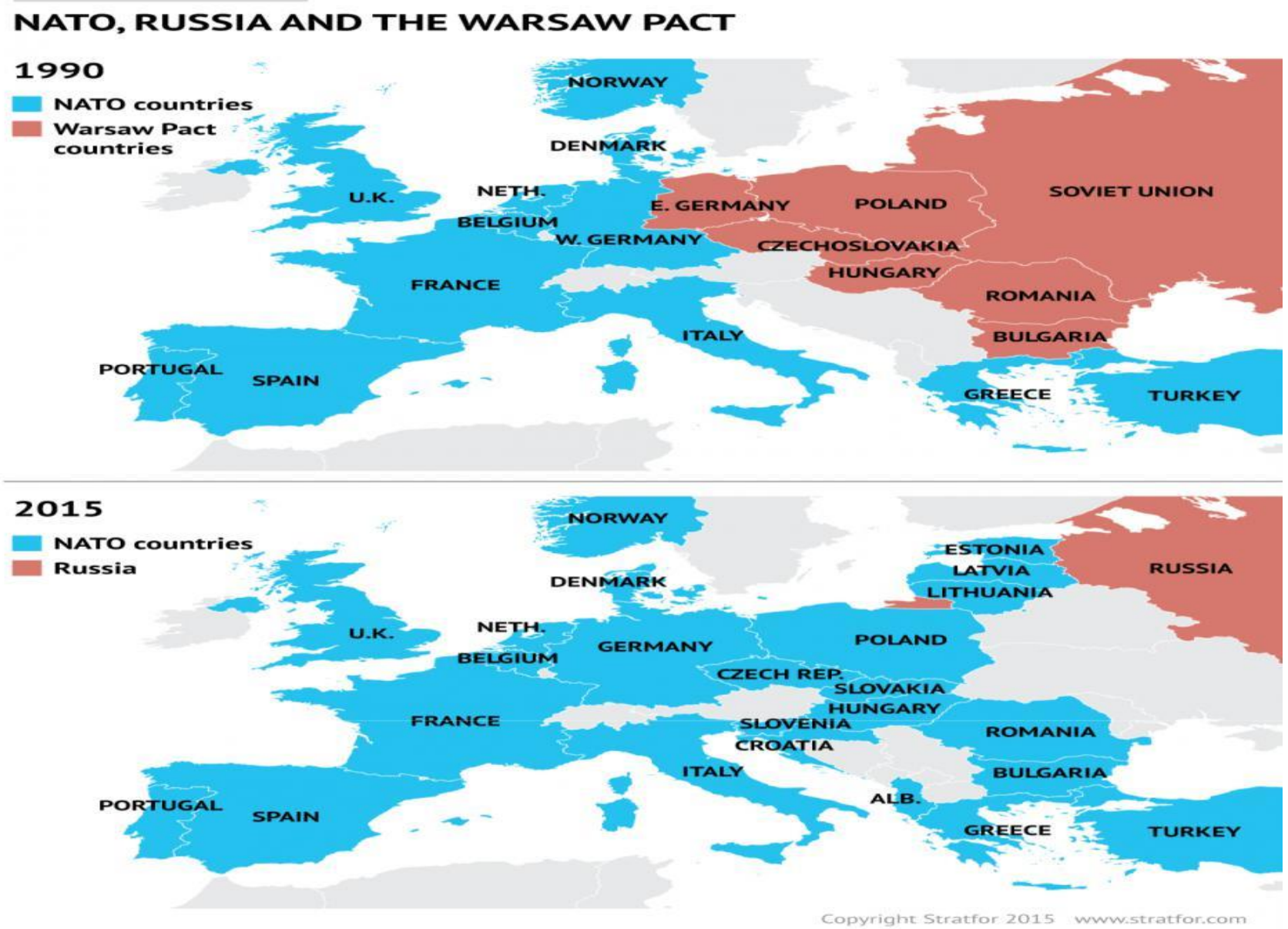

FONTE: BUCZKOWSKI (2017)

Porém, quando a Ucrânia, a qual faz parte da zona de influência do Kremlin, aparentava caminhar em direção a se tornar país-membro da OTAN e até mesmo a União Europeia, a resposta da Rússia, em 2014, foi a invasão deste país com a anexação da Criméia, região ucraniana em que a maioria da população é de etnia russa. O maior receio russo era que uma Ucrânia aliada dos países ocidentais, com regime político democrático e com maior proximidade com o Ocidente, poderia acabar influenciando a população russa contra seu próprio governo (POWASKI, 2019, p. 193-195).

Mais adiante, em 2016, a OTAN expande forças militares para o leste europeu e instala barreiras antimísseis na Polônia e na Romênia. Mais uma vez, Putin critica tais atitudes e reforça a necessidade da Rússia de produzir melhores sistemas de armas nucleares que possam garantir 
efetividade de emprego do arsenal nuclear russo (POWASKI, 2019, p. 201-202). Além dos entraves no território europeu, devemos destacar a não concordância dos governos Obama e Trump com a continuidade da liderança de Bashar Al-Assad na Síria, aliado russo, o que faz que a Rússia e os EUA tenham interesses antagônicos no Oriente Médio. Até mesmo aqui no continente americano há divergências entre o Kremlin e a Casa Branca, já que Putin apoia o governo de Nicolás Maduro na Venezuela e os EUA são a favor atualmente do governo-interino de Juan Guaidó.

Ao contrário do caso russo, o governo Obama sempre manteve preocupações com a China, muito devido ao crescimento econômico deste país e o maior investimentos em forças militares que os chineses começaram a empreender, já que tal desenvolvimento poderia afetar a capacidade estadunidense de realizar embates militares do leste asiático. Para contrabalancear isto, Departamento de Defesa, em 2013, defendeu que mais de 50\% do poder marítimo estadunidense deveria ser concentrado nesta parte do globo. Contudo, a região que gera maior atrito entre chineses e norte-americanos é região do Mar do Sul da China. A preocupação chinesa é que com o crescimento naval estadunidense nesta área, os EUA possam bloquear as rotas comerciais dos navios cargueiros que passam pelo território chinês, além do mais está região é rica em petróleo e gás natural. A partir disto, a China empeza a construir uma série de ilhas artificias nesta localidade, conhecidas como Spratly Islands, que apresentam configurações de estruturas militares (POWASKI, 2019, p. 176-179, 182). Somado a isto:

\begin{abstract}
A China está acelerando sua modernização militar. Os chineses instalaram centenas de mísseis terra-terra munidos de ogivas convencionais capazes de atacar com extrema precisão Taiwan, como também uma pequena quantidades destes mísseis capazes de atingir bases militares norte-americanas no Japão e no leste asiático. Além disto, a China desenvolveu míssil guiado anti-embarcações capaz de destruir porta-aviões estadunidenses. A administração Obama reagiu a estas atitudes alegando que o controle que a China conclama no Mar do Sul da China viola leis do direito internacional elaboradas a favor da livre circulação dos mares (POWASKI, 2019, p. 183, tradução nossa).
\end{abstract}

A partir destes maiores atritos políticos dos EUA com a Rússia e com a China, a administração Obama começa a perceber que estes países podem representar ameaças reais aos interesses e a segurança dos Estados Unidos. Como resposta, o então governo norte-americano muda sua postura em relação ao armamento nuclear e escopo deste tipo de armamento no planejamento de guerra dos Estados Unidos. Isto fica ainda mais nítido quando o governo Obama, em 2016, cria um plano para investir um trilhão de dólares em 30 anos para modernizar todas as frentes do arsenal nuclear norte-americano. Esta medida era vista como essencial para frear possíveis vantagens militares que russos e chineses poderiam eventualmente apresentar com o tempo (EMMONS, 2016). 


\section{GOVERNO DONALD TRUMP (2017-....)}

Devido aos pontos elucidados acima, o NPR 2018 reforça o que outro documento de defesa, também da administração Trump, o National Security Strategy 2017 (NSS 2017) 17 já apontava: o mundo não é mais unipolar, a nova realidade global é a volta da competição entre as grandes potências. É afirmado que tanto a China quanto a Rússia buscam remodelar a ordem internacional aos seus respectivos favores e para que isto seja possível, no que tange as capacidades militares, estes dois países estão aprimorando suas respectivas máquinas de guerra, sobretudo suas armas nucleares. Esse quadro representaria uma ameaça tanto a segurança quanto aos interesses dos Estados Unidos e dos aliados dos Estados Unidos. Assim, a competição entre as grandes potências - EUA, Rússia e China - deve permear o pensamento estratégico-militar estadunidense de agora em diante em uma ordem global multipolar ${ }_{18}$ (TRUMP, 2017, p. 2-3).

Sendo assim, a administração Trump advoga a favor do país fazer investimentos maiores nas armas nucleares 19 e desenvolver novos sistemas de armas nucleares, visando aumentar a flexibilidade de emprego e resposta nuclear em qualquer nível de embate. Os EUA estão desenvolvendo um novo míssil balístico nuclear lançado de submarino com baixo rendimento 20 . Este novo sistema de arma nuclear serviria para contrapor as supostas vantagens que a Rússia tem na quantidade e qualidade dos sistemas de armas nucleares sub-estratégicos, também conhecidos como armas nucleares táticas 21 . Também serviria para contrabalancear mísseis de médio alcance que

\footnotetext{
${ }_{17}$ Documento em que cabe ao poder executivo, presidente, apontar as principais ameaças aos EUA e aos aliados estadunidenses e como a administração vigente pretende lidar com tais ameaças.

${ }_{18}$ O NPR 2018, ao longo do texto também dá importância para ameaças que podem ser proporcionadas por outros Estados, sobretudo a Coréia do Norte e o Irã, pelo terrorismo nuclear e pela proliferação nuclear. Contudo, a partir da leitura deste documento é clara a intenção da administração Trump manter o foco do planejamento estratégico-militar em relação a possíveis conflitos com a China e com a Rússia.

${ }_{19}$ O NPR 2018 argumenta que os gastos anuais com as armas nucleares deve ser aumentado de 3,7\% para 6,4\% do total dos recursos militares disponibilizados para o Departamento de Defesa dos Estados Unidos (EUA, 2018, p. 51).

${ }_{20}$ Para mais informações sobre este sistema de arma ver: 〈https://fas.org/sgp/crs/nuke/IF11143.pdf >

${ }_{21}$ Basicamente podemos dividir as armas nucleares em dois níveis de alcance: 1. Estratégico: quando o sistema de arma é empregado através de plataformas que podem percorrer mais de 5,5 mil $\mathrm{km}$ para atingir seus alvos, como bombardeiros e mísseis balísticos intercontinentais lançados tanto de plataformas terrestres quanto de submarinos. 2. Sub-estratégico, conhecido também como armamento nuclear tático: quando o sistema de arma é empregado por plataformas que tendem a percorrer menos de 5,5 mil km, como, por exemplo o Caça F-15E munido da bomba gravitacional B61. Geralmente as armas nucleares sub-estratégicas apresentam menor rendimento, em kilotons, se
} 
a China possui 22 (EUA, 2018, p. 53-55).

A possível doutrina de emprego de armas nucleares russas "escalate to de-escalate" apontada pelo NPR 2018 com preocupação e como impulso para que os EUA faça melhorias nas suas capacidades nucleares, no que tange principalmente as sistemas de armas nucleares táticas (EUA, 2018, p. 54-55). Somado a isto, em 2019, os EUA se retiram do INF devido a acusações que Moscou teria violado as regras deste acordo 24 . Em 2020, Trump sinalizou que os EUA se retirarão do Open Skies Treaty ${ }_{25}$ e também, até agora, o atual presidente norte-americano não deu nenhuma indicação de que pretende renovar o New START com os russos.

O grande problema destes acordos, sobretudo o INF e o New START, é que eles são reflexos de uma ordem internacional em que a maior parte do temor estratégico-nuclear para os estadunidenses era voltada a Rússia. Com a China despontando cada vez mais em termos econômicos, políticos e militares - apontada por muitos como a grande rival em termos de poder internacional dos EUA agora e ainda mais no futuro - e não querendo entrar em regimes de limite de sistemas de armas/ogivas nucleares 26 e mecanismos de verificação mútua tanto com os EUA e com a Rússia, faz com que os acordos internacionais deste gênero que não tenham participação de

comparadas com as estratégicas. O NPR 2018 (p. 53) faz uma estimativa que a Rússia possui cerca de 2 mil sistemas de armas nucleares táticas - o que é difícil de ser realmente verificado já que, até o momento, não há nenhum acordo que controle e verifique tais informações, tanto da Rússia, como muito menos da China - e por outro lado, os EUA só possuem bombas gravitacionais da família B61, ao redor de 230, lançadas de caças e ou pelo bombardeiro B-2.

${ }_{22}$ Mísseis nucleares terra-terra que cumpram distâncias entre 0,5 mil km a 5,5 mil km. Os quais eram proibidos pelo acordo INF - ver nota de rodapé 24.

${ }_{23}$ De acordo com o NPR 2018 (p. 30) está doutrina de emprego de armas nucleares que supostamente a Rússia tem seria utilizada para de-escalar um conflito militar convencional, caso Moscou estivesse perdendo. Isto significaria que: ao se ver perdendo embate com o uso de armamento convencional, a Rússia começaria ou ameaçaria empregar suas armas nucleares táticas para que o outro lado desistisse de continuar o confronto.

${ }_{24}$ O Intermediate-Range Nuclear Forces Treaty (INF) entrou em vigor no ano de 1988. Ele incapacitou tanto os EUA quanto a URSS - posteriormente a Rússia - de possuírem mísseis terra-terra que cumpram distâncias entre 0,5 mil km a 5,5 mil km (ODASDNM, 2020, p. 204). Os EUA acusaram no NPR 2018 (p. 10) os russos de violarem as regras do acordo com a suposta produção de um míssil terra-terra, conhecido como SSC-8, o qual percorreria as distâncias proibidas pelo tratado. Contudo, para Wolf $(2019$, p. 6) o real motivo da saída estadunidense deste acordo é que a China não faz parte dele e teria eventual vantagem por poder utilizar mísseis terra-terra que possam ser empregados nas distâncias coibidas pelo INF.

${ }_{25}$ Acordo que russos e norte-americanos que entrou em vigor em 2002. Nele ficou estabelecido que as duas partes poderiam utilizar aviões para espionar o território do seu páreo, visando averiguar se o outro lado está se preparando para uma guerra ou não. A administração Trump acusa a Rússia de ter utilizado seus aviões para espionar membros da OTAN, então, os russos estariam violando as regras do acordo (GIELOW, 2020).

${ }_{26}$ A China alega que não vê motivos para entrar em acordos de limitação e verificação do seu arsenal nuclear devido à baixa quantidade de ogivas e plataformas nucleares de envio que o país tem. A estimativa é que Pequim possui cerca de 400 ogivas nucleares no total, enquanto russos e norte-americanos possuem - se considerarmos os estoques e ogivas nucleares que não estão acopladas em nenhum sistema de arma estratégicos - por volta de 6 mil. Outra alegação chinesa é que sua doutrina de emprego de armas nucleares se mantem a mesma desde 1964, ano que o país realiza o primeiro seu primeiro teste com armamento nuclear, em que Pequim só utilizaria suas armas nucleares como forma de retaliação após sofrer ataque nuclear (ZHANG, 2012, p. 1-5). Contudo, de acordo com Kulacki (2016, p. 4-6) a China poderia usar suas armas nucleares como uma forma de evitar uma invasão estadunidense sobre seu território. 
Pequim se tornem obsoletos. Trump já chegou a declarar que só renovará o New START se a China empezar a também fazer parte deste acordo (GIELOW, 2020).

O NPR 2018 (p. 17) deixa a entender que para administração Trump acredita as armas nucleares tem o papel essencial para evitar o conflito bélico entre as grandes potências. Este documento levanta o seguinte dado: antes do surgimento das armas nucleares o embate entre as grandes potências era mais recorrente, tanto que até 1945 - ano de fabricação da primeira bomba atômica - conflitos militares de grande proporção entre os Estados pivôs do sistema internacional ocasionavam a morte de por volta $1,5 \%$ da população mundial. Posteriormente com o advento das armas nucleares os conflitos bélicos entre 1950 até os anos 2000 vitimaram 0,4\% da pessoas ao redor do globo. De 2000 até os dias atuais está porcentagem caiu para menos de 0,01\% da população mundial - Ver imagem 2 abaixo. Está grande diminuição do número de pessoas mortas em conflitos bélicos se deve, de acordo com NPR 2018, ao "equilíbrio do terror" que o armamento nuclear trouxe. Com o surgimento das armas nucleares, qualquer possível conflito militar entre as grandes potências poderia significar praticamente a destruição dos lados beligerantes devido ao poder devastador de destruição do armamento nuclear. Isto nos remota ao cientista político Kenneth Waltz27. O governo Trump demonstra confiar mais na força/demonstração de força do que em acordos internacionais para evitar guerra. Tanto que em diversos momentos no NPR 2018 é afirmado que ataques e ou ameaças de qualquer possível adversário contra os EUA e ou contra os aliados estadunidenses terá consequências imensuráveis para o lado atacante.

\author{
IMAGEM 2 - COMPARAÇÃO DA PORCENAGEM DE FATALIDADES DA POPULAÇÃO MUNDIAL \\ (CÍVIS E MILITARES) EM TEMPOS DE GUERRA CONVECIONAL E POSTERIOMENTE AO ADVENTO DO \\ ARMAMENTO NUCLEAR
}

${ }_{27}$ Waltz (2013, p. 4-8) destaca que desde o final da Segunda Guerra Mundial, em 1945, a qual teve nos seus momentos finais a utilização por parte dos EUA de armamento nuclear contra o Japão, nas cidades de Hiroshima e Nagasaki, não ocorreu mais choques militares entre as principais potências militares. Isso se deve ao poder devastador que os artefatos nucleares emitem no momento da sua explosão, fazendo com que os Estados que possuem tal poder em suas mãos não embarquem em conflito entre si, podendo significar danos imensuráveis. O medo de sofrer retaliação faz com que o ímpeto do primeiro ataque não se materialize. Desse jeito, os Estados possuidores de artefatos nucleares agem de maneira racional, pois se iniciarem um embate nuclear sofrerão grande devastação em resposta. Guerras ficam difíceis de serem travadas quando os custos do embate são maiores do que benefícios de uma possível vitória. Sendo assim, Waltz considera que o armamento nuclear foi/é o ponto primordial para que guerras envolvendo as principais potências militares, logicamente as que possuem este tipo de arma, não ocorram. Este é o princípio da dissuasão nuclear. 


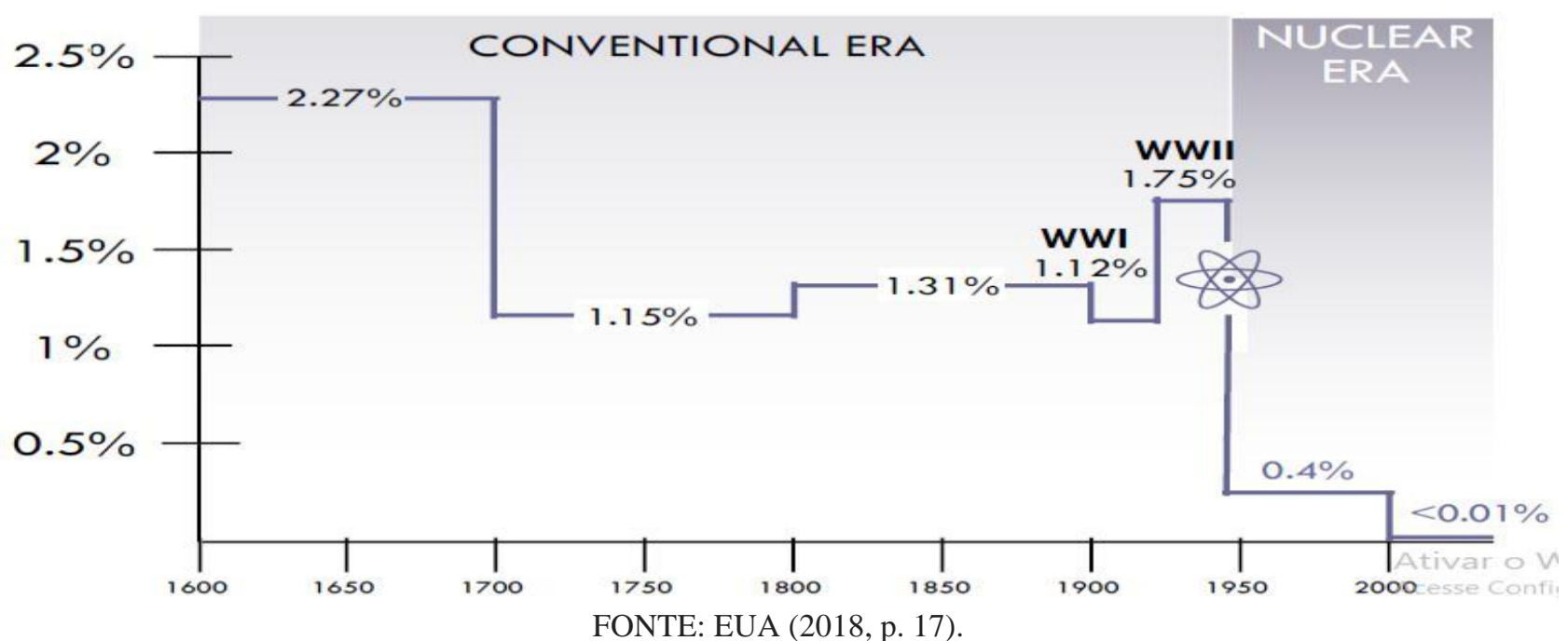

No arranjo internacional da terceira era nuclear seria melhor que russos, chineses e norteamericanos celebrem juntos acordos de limitação e verificação de armas nucleares, principalmente que envolvam as armas nucleares sub-estratégicas. Este é o melhor caminho para que as partes: limitem seus arsenais nucleares o que diminuirá os gastos com este tipo de armamento; verifiquem o equilíbrio de força, capacidade dissuasória entre as partes; e principalmente tenham uma canal de comunicação mais claro. Todas estas medidas evitariam erros de cálculo o que poderia levar um enfretamento com o emprego de armas nucleares. Apesar do governo Trump no NPR 2018 indicar que pretende negociar com chineses e russos não vimos, até agora, esforço da atual administração republicana para traçar tratados neste sentido.

\section{CONSIDERAÇÕES FINAIS}

O objetivo deste trabalho foi demonstrar que o fator que mais influenciou o planejamento em relação ao armamento nuclear de cada novo governo estadunidense, no pós-Guerra Fria, foi o ambiente de segurança internacional que cada administração encontrou ao tomar pose. A partir de uma análise mais macro, podemos observar que tanto a administração Clinton quanto a administração Bush tinham como preocupação a proliferação nuclear e a possiblidade de organizações terroristas tomarem posse deste tipo de armamento. Ambos também acreditavam que as armas nucleares teriam cada vez mais menor escopo no planejamento militar/estratégico dos Estados Unidos. Ao mapearmos o governo Obama, este também detinha como enfoque a proliferação e principalmente o terrorismo nuclear como principais ameaças e também acreditava que as armas nucleares deveriam ter espaço menor no desenvolvimento militar norte-americano. 
Todavia, quando mudanças no cenário internacional ficaram mais claras - devido a percepção de que a Rússia e China poderiam desafiar a unipolaridade estadunidense - ocorre uma mudança de comportamento em relação ao planejamento nuclear até então vigente.

Trump herda de Obama uma transição de polaridade mais límpida, aceita as condições apresentadas e planeja preparar os Estados Unidos para uma novo ordenamento internacional multipolar. Este artigo focou em um dos sintomas desta transição de balança de poder: O novo papel do armamento nuclear. Como dito na introdução deste texto, na mudança da unipolaridade para multipolaridade as armas nucleares acabam ganhando novo significado e patamar de importância, o que ajuda a explicar o maior investimento que a administração Trump planeja realizar neste tipo de armamento.

A administração Trump acredita piamente que o maior investimento e confiança nas armas nucleares evitará a guerra entre as grandes potências, devido a capacidade dissuasória que este tipo de armamento fornece pelos danos colaterais que a retaliação nuclear pode ocasionar. Outro caminho possível seria o maior esforço dos EUA, da Rússia e da China de celebrarem acordos de diminuição/fiscalização dos seus respectivos arsenais nucleares. Além de evitar gastos gigantescos com este tipo de armamento, cada parte teria parâmetros das capacidades militar-nuclear dos outros. Isto possivelmente também melhoria os canais de comunicação entre as partes, que ajudariam a evitar o erro de cálculo e o início de uma guerra, sobretudo nuclear. Entretanto, parece que norteamericanos, russos e chineses por enquanto preferem seguir a receita do "equilíbrio de terror".

\section{REFERENCIAS}

BUCZKOWSKI, Alesks. Top 14 maps and charts that explain NATO. 2017. Disponível em: https://geoawesomeness.com/top-14-maps-charts-explain-nato/. Acesso em: 29/06/2020.

EMMONS, Alex. Obama's Russian Rationale for \$1 Trillion Nuke Plan Signals New Arms Race. 2020. Disponível em: <https://theintercept.com/2016/02/23/obamas-new-rationale-for-1trillion-nuclear-program-augurs-a-new-arms-race-with-russia/>. Acesso em: 29/06/2020.

ESTADOS UNIDOS DA AMÉRICA (EUA). Nuclear Posture Review 2001. 2002. Disponível em: 〈https://web.stanford.edu/class/polisci211z/2.6/NPR2001leaked.pdf>. Acesso em 26/06/2020.

. Nuclear Posture Review 2010. 2010. Disponível em:

<https://dod.defense.gov/Portals/1/features/defenseReviews/NPR/2010_Nuclear_Posture_Review_

Report.pdf>. Acesso em: 17/04/2020. 
Nuclear Posture Review 2018. 2018. Disponível em: <https://www.defense.gov/News/SpecialReports/2018NuclearPostureReview.aspx >. Acesso em: 06/04/2020.

GIELOW, Igor. Trump deixa mais um tratado que visa evitar guerra nuclear com a Rússia. 2020. Disponível em: <https://www1.folha.uol.com.br/mundo/2020/05/trump-deixa-mais-umtratado-para-evitar-guerra-nuclear-com-a-russia.shtml>. Acesso em: 28/06/2020.

GUTHE, Kurt. Summaries of the 1994, 2001, and 2010 Nuclear Posture Reviews. Fairfax:

National Institute Press, issue 405, 2016.

JESUS, Diego. Dissuasão, redução de armas nucleares e defesa antimísseis nos governos Bush e Obama. Revista Brasileira de Política Internacional, vol. 56, n. 2, 2013.

KRISTENSEN, Hans. Nuclear Posture Review. 1995. Disponível em: <https://fas.org/nuke/guide/usa/doctrine/dod/95_npr.htm> Acesso em: 12/03/2020.

1994 Nuclear Posture Review. 2005. Disponível em: <https://www.nukestrat.com/us/reviews/npr1994.htm>. Acesso em: 12/03/2020.

KULACKI, Gregory. The Risk of Nuclear War with China: A Troubling Lack of Urgency. 2016.

Disponível em: <https://www.ucsusa.org/sites/default/files/attach/2016/05/Nuclear-War-with-

China.pdf>. Acesso em: 29/06/2020.

OFFICE OF DEPUTY ASSISTANT SECRETARY OF DEFENSE FOR NUCLEAR MATTERS (ODASDNM). Nuclear Matters Handbook. 2020. Disponível: <https://www.acq.osd.mil/ncbdp/nm/nmhb/index.htm>. Acesso em: 26/06/2020.

POWASKI, Ronald. Ideals, Interests, and U.S. Foreign Policy from George H. W. Bush to Donald Trump. Palgrave Macmillan, 2019.

PUTIN, Vladimir. Presidential Address to the Federal Assembly. 2018. Disponível em: <http://en.kremlin.ru/events/president/news/56957>. Acesso em: 27/06/2020.

ROBERTS, Brad. The Case for U.S. Nuclear Weapons in the $21_{\text {st }}$ Century. California: Stanford Security Studies, 2016.

TREAT ON THE NON-PROLIFERATION OF NUCLEAR WEAPONS (NPT). 1968. Disponível em: 〈http://www.un.org/disarmament/wmd/nuclear/npt/text>. Acesso em: 26/06/2020. TREVITHICK, Joseph. Get to Know America's Long Serving B61 Family of Nuclear Bombs. 2018. Disponível em: <https://www.thedrive.com/the-war-zone/19263/get-to-know-americas-longserving-b61-family-of-nuclear-bombs $>$. 
TRUMP, Donald. National Security Strategy. 2017. Disponível em:

<https://www.whitehouse.gov/wp-content/uploads/2017/12/NSS-Final-12-18-2017-0905.pdf>. Acesso em: 23/05/2020.

WALTZ, Kenneth. More May Be Better. The Spread of Nuclear Weapons: An Enduring Debate. Third Edition. New York: Norton \& Company, 2013.

WOLF, Amy. Russian Compliance with the Intermediate Range Nuclear Forces (INF) Treaty: Background and Issues for Congress. Code: R43832, 2019.

ZHANG, Hui. China's Nuclear Weapons Modernization. 2012. Disponível em: $<$ https://www.belfercenter.org/sites/default/files/legacy/files/ChinaNuclearModernization-

hzhang.pdf>. Acesso em: 29/06/2020 